\title{
The Variation on Tempo-Spatial Pattern of Main Pastoral Grasslands in China
}

Wei Zhou ${ }^{1,2, *}$, Lu Huang ${ }^{1}$, Han Yang ${ }^{1}$, Xuemin $\mathrm{Nie}^{3}$

1,Department of geography and land and resources, College of Architecture and Urban Planning, Chongqing Jiaotong University ,Chongqing 400074, China

2,State Key Laboratory of Resources and Environmental Information System, Institute of Geographic Sciences and Natural Resources Research, Chinese Academy Sciences, Beijing 100101, China

3,Remote sensing monitoring center of ecological environment in Qinghai, Qinghai 810007, China

\begin{abstract}
In order to explore the grassland ecosystem productivity and landscape ecological patterns of main pastoral grasslands in China, it provides a theoretical basis for the efficient implementation of ecological engineering and rational management of grassland resources in the region. This study analyzed the changes in grassland area, landscape index (LSI), and net primary productivity (NPP) in seven major pastoral areas in China in 1985, 1995, 2005, and 2015. Results showed that (1) the sizes of the grassland study area in 1985, 1995, 2005, and 2015 were 248.34, 243.93, 245.80, and $244.660 \mathrm{~km}^{2}$ respectively. (2) The dominance of grassland in the landscape pattern increased from 2005 to 2015 as compared with that in 1985-1995 and 1995-2005. The degrees of spatial heterogeneity were reduced. (3) The grassland NPP showed spatial and temporal differences. The average NPP of grassland increased by $21.30 \%, 16.47 \%$, and $36.17 \%$ during 1985-1995, 2005-2015, and 1985-2015, respectively. From 1995 to 2005, the average NPP decreased by $5.05 \mathrm{gC} / \mathrm{m}^{2}$, which is equivalent to $-3.61 \%$ of the average NPP in 1995 . The total amount of grassland NPP in the study area was the greatest in 2015, showing increments of
\end{abstract}

Acknowledgements

This work was supported by the National Youth Science Fund (41501575), the basic science and advanced technology Fund of Chongqing Scientific Council (cstc2016jcyjA1540). We also thank the China Meteorological data sharing service system for granting us access to climate datasets.

Corresponding author: Wei Zhou, China, E-mail: zhouw866@163.com, Tel:(+86)15723305876. 
$36.37 \%$ and $16.61 \%$ compared with those in 1985 and 2005 , respectively. Keywords: Grassland landscape index; Grassland productivity; Land use/cover change; Net Primary Productivity(NPP)

\section{Introduction}

As one of the most widely distributed land cover types on land, grassland accounts for approximately $20 \%$ of the global terrestrial surface area (Scurlock \& Hall 2010). Its net primary productivity (NPP) accounts for $16 \%$ of the total global terrestrial ecosystem NPP. (Conant et al 2001; Zhou et al 2010) China's grassland area is approximately 4 million $\mathrm{km}^{2}$, accounting for $41.7 \%$ of China's total land area and $6 \%-8 \%$ of the global grassland area. (Ren et al 2008) The grassland carbon reserves in China account accounts for 9\%-16\% (Ni 2002) of the global grassland carbon stocks. Grassland resources play an important role in China's ecological and environmental protection and socio-economic development and are considered one of the important renewable natural resources (Han et al 2008; Nan 2005) 1996). Grassland provides vital materials, such as fodder, meat, milk, skin, wool and other livestock products, for the economic development of animal husbandry (Kang et al 2007). This land type also serves as significant habitat and evolution site for animals and plants in grassland ecosystems (Kang et al 2007; Zhou, J. W et al 2004). Sexual protection, wind and sand fixation, conservation of water resources, and carbon recycling are some of the important ecological functions of grassland, which is also the material carrier of China's multi-ethnic culture (Han, Y. W et al 2004; Yang, Y. J \& Jing, G. C 2003).

China's grassland ecosystem and ecological environment have changed due to the intensification of global climate change with the main features of global warming, the adverse effects of extreme climate events, and the unreasonable and prolonged use of grassland resources by humans (Han, Y. W \& Gao, J. X 2005). Desertification occurred, salinization accelerated, and the grassland ecological function decreased. Some studies have found that $90 \%$ of China's available natural grassland has experienced various degrees of degradation. Approximately $27.3 \%$ of China's natural grassland is affected by desertification, and about 400 million production and livelihood 
are affected by desertification. Furthermore, the economic loss caused by sandstorms can reach 54 billion yuan (Akiyama \& Kawamura 2007).

Grassland degradation has a serious impact on ecological and environmental protection and socio-economic development (Cao 2011; Liu et al 2008). The degeneration of grassland in northern China and the frequent severe dust storms have received extensive attention from the international community. Since 1999, the Chinese government has implemented ecological restoration measures. This program has led to changes in land use and cover (LUC) and grassland coverage and ecological functions. In addition, climate change also affects the global ecological environment at an unprecedented rate. In some parts of eastern Asia, the frequency of extreme climatic events has increased by 5\% (Qi et al 2012) during the past 30 years compared with that during 1961-2000. The temperature in China increased from 1950 to 2010 at the speed of $0.17{ }^{\circ} \mathrm{C} / 10$ year (Zhai et al 2005), which is $0.13{ }^{\circ} \mathrm{C} / 10$ year higher than the rate of global temperature rise (Al \& Paasche 2007).

Affected by global climate change and human activities, China's grassland ecosystem has undergone significant changes. The main distribution areas of grasslands are found in the arid and semi-arid regions of northern China and the alpine grassland on the Tibetan Plateau. These locations are particularly sensitive to climate change and human disturbance. Therefore, studying the response of grassland dynamics to humans and climate change in these regions is important to understand global changes. The changes in grassland ecological environment have important theoretical significance. The change in landscape pattern and productivity in grassland coverage area is the most intuitive response of grassland ecosystem to climate change and land use and cover change (LUCC). By using LUCC data, remote sensing, climate data, and nature, society and economy data, this paper analyzed the changes in the grassland cover area, land-scape index (LSI), and NPP of the study area from 1985 to 2015 . The effect of climate and human activities on grassland ecosystem changes will provide a theoretical basis for the sustainable development of China's grassland ecosystem in the context of global change.

\section{Study area}

The study area in this paper is China's main pastoral area $\left(26^{\circ} 50^{\prime}-53^{\circ} 23^{\prime} \mathrm{N}, 73^{\circ} 40^{\prime} \sim 126^{\circ} 04^{\prime} \mathrm{E}\right)$, 
which includes there provinces (Gansu Province, Shaanxi Province, Qinghai Province) and four autonomous regions (Inner Mongolia Autonomous Region, Ningxia Hui Autonomous Region, Xinjiang Uygur Autonomous Region, Tibet).

The study area has a total area of 5.5 million $\mathrm{km}^{2}$ and the climate is mainly arid and semi-arid, Accounting for $57.21 \%$ of the total land area of China, the grassland here has been used for a long period of time for grazing, but it has been destroyed in recent years, the dual effects of human and climate have resulted in the improvement of grassland destruction, and the implementation of projects such as returning grazing land to forests and grasslands has also been continuously reduced.

\section{Data and methods}

\section{Land-use data}

To characterise the spatial and temporal patterns of land-use changes across China, the Chinese Academy of Sciences built a data platform supported by the National Resources and Environment Database (NRED) in the late 1990s. Land-use datasets for 1985, 1995, 2005 and 2015 with a mapping scale of 1:100 000 were originally derived from Landsat images of corresponding years, and then a $1 \mathrm{~km}$ raster database was generated. According to the land-use classification system for the NRED dataset, the land use was categorised into six types: cropland, forest, grassland, water bodies, built-up land and bare land including desert. In this study, the land-use data for 1985, 1995, 2005 and 2015 with a 1-km resolution were downloaded from Data Sharing Infrastructure of Earth System Science (http:// wdcrre.geodata.cn/, accessed 20 May 2017) (Liu, J. Y et al 2003).

\section{Landscape metrics}

This article uses the Patch Analyst extension module in ArcGIS to calculate the landscape index of grassland in seven major pastoral areas in four periods. This module embeds some Fragstate functions into ArcGIS software to facilitate the implementation of patches and types in ArcGIS and calculate the landscape indices of type and landscape scales ( $\mathrm{Yu}$ et al 2011).. The definition and detailed description of various landscape indices are similar to those in Fragstate (Wang et al 2008). The following six indices were selected on the type scale: number of patches (NP), mean patch size (MPS), edge density (ED), area weighted mean shape index (AWMSI), area weighted 
mean fractal dimension (AWMFD), and interspersion juxtaposition index (IJI). The following two indices were selected on landscape scale: Shannon's diversity index (SHDI) and Shannon's evenness index (SHEI). The calculation process is implemented in ArcGIS 10.2.

\section{Model to estimate NPP}

Three models, namely, parameter, statistical, and process models, are used to estimate terrestrial ecosystem NPP. Basing on the existing CASA model(Zhu, W. Q et al 2007) and the land use/land cover classification standard of the Chinese Academy of Sciences, this paper examines the grassland NPP in the study area. This model mainly uses meteorological data and vegetation NDVI data as basic parameters. Effective radiation, temperature stress coefficient, water stress coefficient, and maximum light energy utilization efficiency of photosynthesis for vegetation were combined to account for vegetation NPP (Han, Y. W et al 2004; Pu, S. L et al 2001; Zhong, H. P et al 2005). The vegetation NPP is mainly determined by the photosynthetically active radiation (APAR) and light energy utilization (E) absorbed by the vegetation.

$$
\operatorname{NPP}(x, t)=\operatorname{APAR}(x, t) \times E(x, t),
$$

whereNPP $(x, t)$ represents the photosynthetically active radiation (PAR) absorbed by pixel $\mathrm{x}$ in month $\mathrm{t}$, in units of $\mathrm{MJ} / \mathrm{m}^{2} / \mathrm{month}$; and $E(x, t)$ represents the actual light energy utilization of pixel $\mathrm{x}$ in month $\mathrm{t}$, in units :g C/MJ.

$$
\operatorname{APAR}(x, t)=\operatorname{SOL}(x, t) \times \operatorname{FPAR}(x, t) \times 0.5
$$

In the formula, the amount of total solar radiation absorbed by the pixel $\mathrm{x}$ in month $\mathrm{t}$ is expressed in units of $\mathrm{MJ} / \mathrm{m}^{2} /$ month. The ratio of the absorption of the effective photosynthetically active radiation by the vegetation layer; the constant value of 0.5 indicates that the solar radiation available to the vegetation accounts for the total solar radiation (proportion of radiation).

Light energy utilization refers to the efficiency of the vegetation to convert the absorbed PAR into organic carbon. Under ideal conditions, vegetation has the maximum light energy utilization rate. However, in actual conditions, the true maximum light energy utilization rate (E) is also affected by temperature and precipitation. The specific formula is as follows.

$$
E(x, t)=T_{E 1}(x, t) \times T_{E 2}(x, t) \times W_{E}(x, t) \times E_{\max }
$$


where $\mathrm{T}_{\mathrm{E} 1}(\mathrm{x}, \mathrm{t})$ refers to the stress effect of high temperature on light utilization (no unit), $T_{E 2}(x, t)$ refers to the effect of low temperature on the utilization of light energy (no unit), $W_{E}(x, t)$ is the moisture Coercion coefficient (no unit) that mainly indicates the degree of influence of the calculated NPP on water status, and $E_{\max }$ refers to the maximum light energy utilization under ideal conditions (unit: g $\mathrm{C} / \mathrm{MJ}$ ).

Temperature, moisture, and other stress factors are calculated according to previous methods. The maximum light energy utilization rate varies with vegetation types. This paper refers to the maximum light energy utilization rate of typical vegetation in China as simulated by Zhu (Zhu, W. Q 2005a). Vegetation types include cropland, grassland, water-bodies, built-up land, and bare land, and the light energy utilization rate is $0.542 \mathrm{~g} \mathrm{C} / \mathrm{MJ}$. The globally recognized value of $0.389 \mathrm{~g}$ $\mathrm{C} / \mathrm{MJ}$ is selected as the maximum light energy utilization rate of the forest land.

\section{Model accuracy verification}

In this paper, 51 grassland biomass samples measured in the main pastoral areas of China in July and August of 2008 were used to translate the above-ground and underground biomass allocation ratios of Inner Mongolia grassland into grassland and underground vegetation according to $\mathrm{Ma}$ Wenhong et al. Productivity, which was evaluated from the NPP data measured in the grass, was used to verify the accuracy of the model. The following figure (Fig 1) shows the correlation analysis between simulated and measured values of grassland NPP model in 2005, $\mathrm{R}^{2}=0.7103$ $(\mathrm{P}<0.001)$. The results show that the CASA model has high simulation accuracy and can be applied to the simulation of grassland NPP in the study area. 


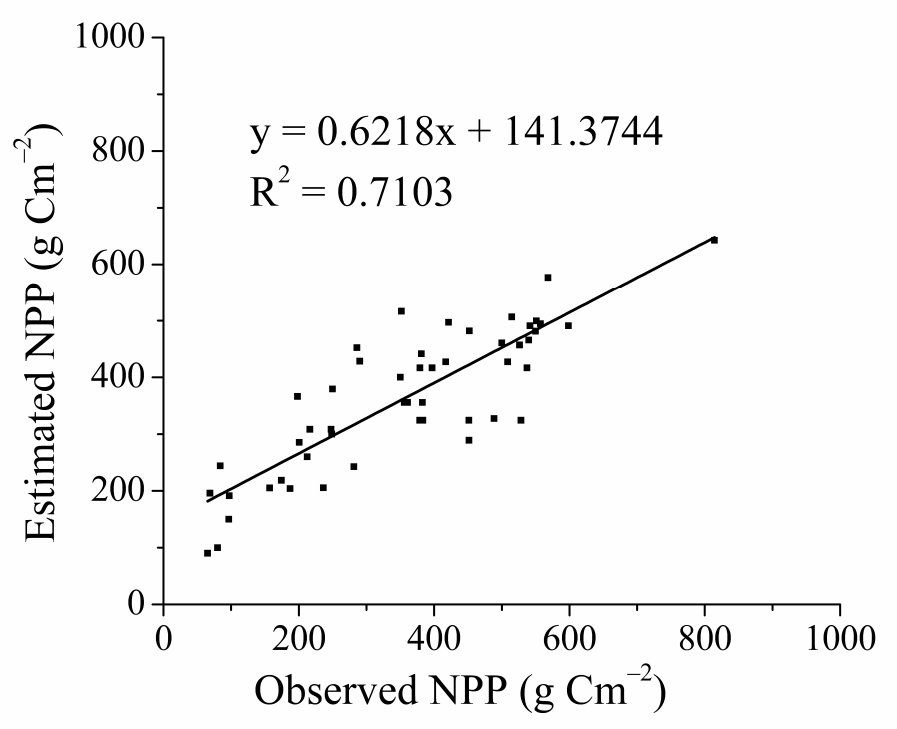

Fig.1. Relationship between estimated Net Primary Productivity (NPP) and observed NPP for grasslands in August of 2008

\section{Analysis of Spatial and Temporal Dynamic Changes of Grassland}

The land cover of the seven pastoral areas in 1985, 1995, 2005, and 2015 is shown in Fig 2, and the dynamic changes in the grassland study area are shown in Table 1,Table 2 . The sizes of the grassland study area in 1985, 1995, 2005, and 2015 were 248.34, 243.93, 245.80 and 2.4466 million $\mathrm{km}^{2}$, respectively. The grassland areas in different pastoral areas changed differently. The grassland area in Tibet Autonomous Region was the largest in 1985 and accounted for $70.05 \%$ of the total land area in the region. The grassland in Xinjiang Uygur Autonomous Region accounted for $29.61 \%$ of the total land area in 1985 and 1995. The grassland areas in Inner Mongolia Autonomous Region, Qinghai, and Shaanxi were the largest in 1995 and accounted for 50.03\%, $52.96 \%$, and $38.72 \%$ of the total land areas, respectively. The grassland area in Gansu reached the maximum in 2015 and accounted for $34.61 \%$ of the whole land area. 

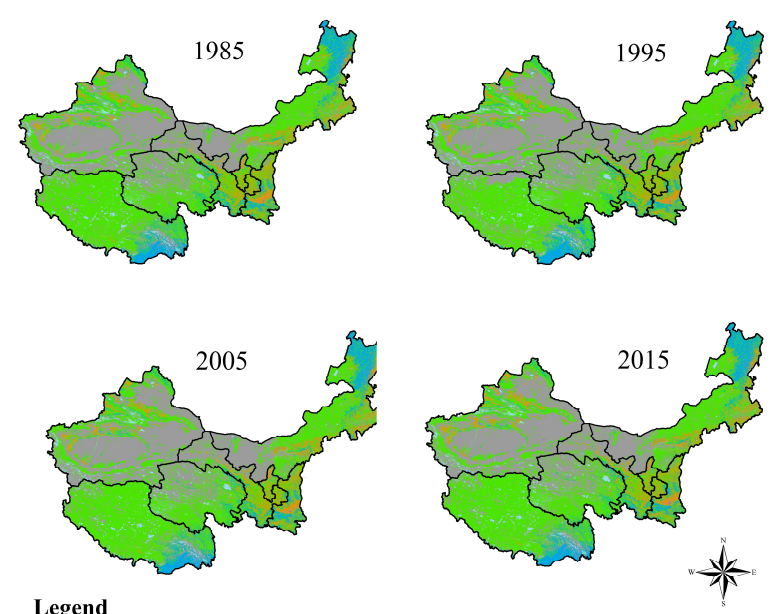

Legend

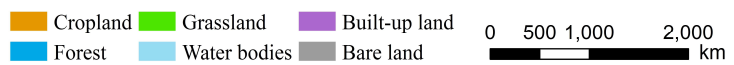

Fig.2. The spatial distribution of grassland areas changes during 1985-2015

From 1985 to 1995 , the grassland in the study area decreased by $18.92 \%\left(468,829 \mathrm{~km}^{2}\right)$. The reduction in grassland is mainly due to the mutual transformation of grassland to bare land or to forest, resulting in a decrease of 215888 or $108343 \mathrm{~km}^{2}$, respectively. The conversion of bare land to grassland led to a net increase of $320,574 \mathrm{~km}^{2}$ in grassland. In the spatial distribution, the area of grassland reduction is mainly distributed in Tibet, Gansu, and Ningxia. For these regions, the transfer of grassland to bare land is the main reason for the decrease in grassland area. The net conversion of grassland to bare land in the three provinces reached to 56161, 14211, and $1705 \mathrm{~km}^{2}$, respectively. By contrast, the increase in grassland area was distributed in the other three provinces, of which the highest was in Qinghai grassland area at $90794 \mathrm{~km}^{2}$. In these regions, $66377 \mathrm{~km}^{2}$ of grassland was transformed from bare land and $14,562 \mathrm{~km}^{2}$ was from forests. The grassland area in Inner Mongolia increased by $72846 \mathrm{~km}^{2}$, of which the net area transformed from bare land to grasslands reached by $23607 \mathrm{~km}^{2}$. In Xinjiang, the transfer was only $13 \mathrm{~km}^{2}$ from 1985 to 1995. 
$1985-1995$

From other types to grassland From grassland to other types
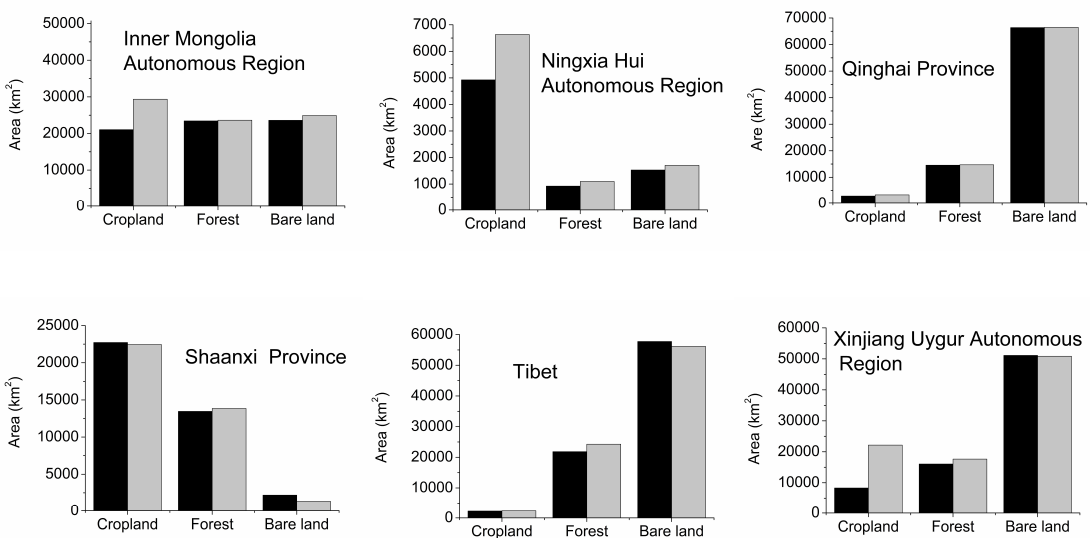

Fig 3: The conversion between grassland and other land cover types during 1985-1995
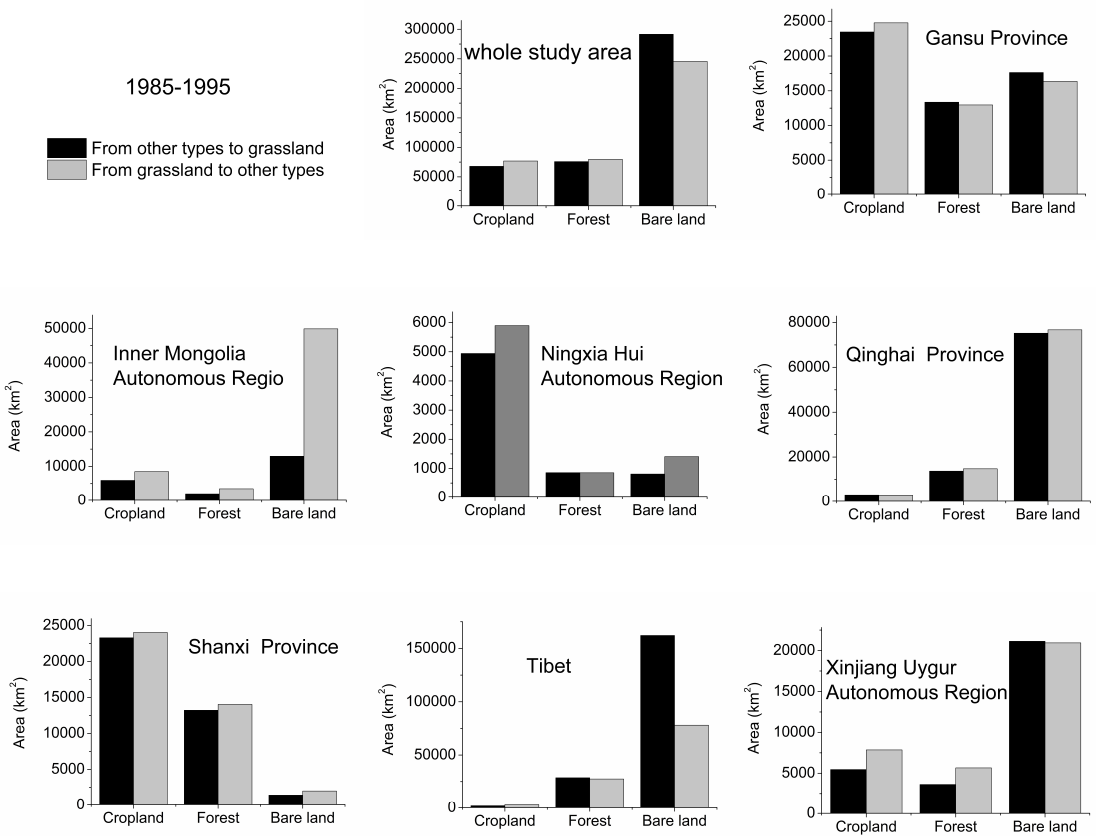

Fig 4: The conversion between grassland and other land cover types during 1995-2005 

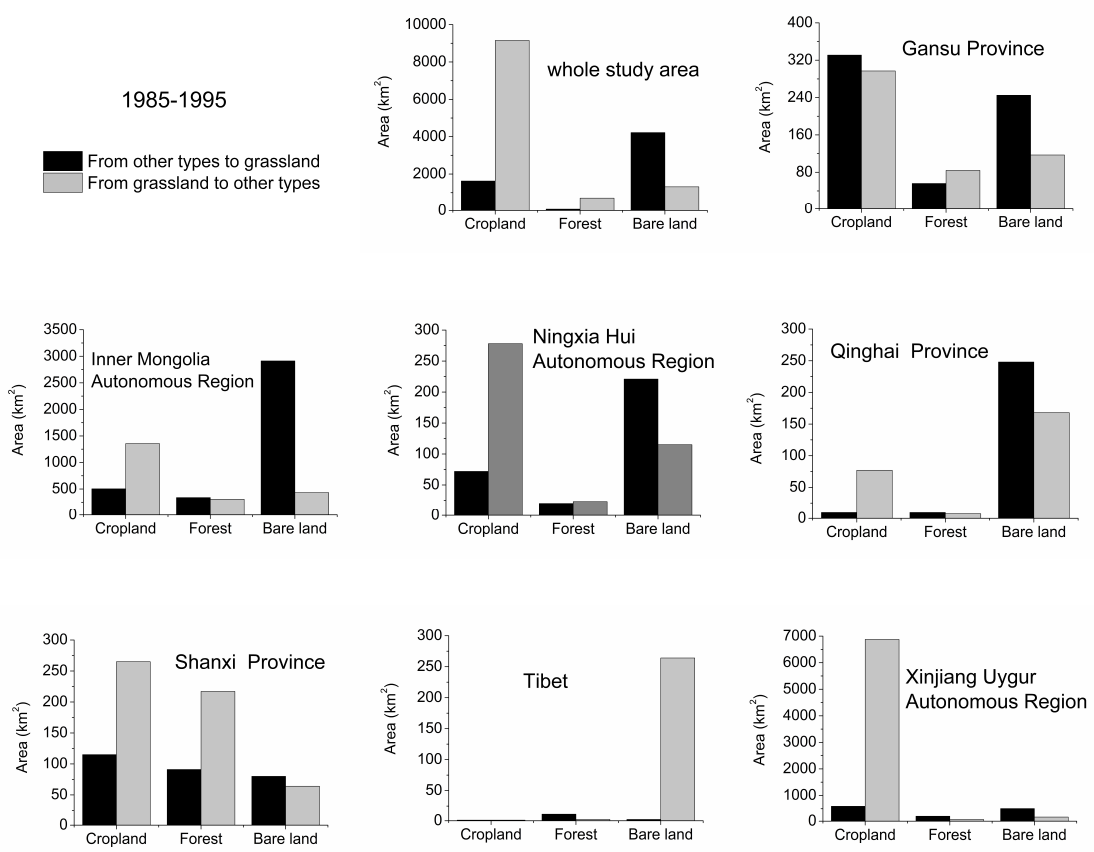

Fig 5: The conversion between grassland and other land cover types during 2005-2015

From 1995 to 2005 , the grassland in the study area increased by $18694 \mathrm{~km}^{2}$, equivalent to $0.77 \%$ in 1995. The increase of grassland is mainly from the bare land to grassland, covering an $338709 \mathrm{~km}^{2}$, while the reduction of grassland is mainly converted to bare land and forest 291758 and $1133956 \mathrm{~km}^{2}$. In the spatial distribution, newly-added grassland is concentrated in Tibet and Gansu, $10.63 \%$ and $0.70 \%$ of the grassland area in 1995 . According to the statistical analysis, there were $80586 \mathrm{~km}^{2}$ bare land transferred to grassland in Tibet, while the number converted to bare land was 105,028 and finally the net increase of grassland area was $83,862 \mathrm{~km}^{2}$. There were $23307 \mathrm{~km}^{2}$ grassland transferred from the cropland in Gansu Province. It is widely distributed in the other 5 provinces, among which, the conversion of grassland and bare land, farmland and forest in Inner Mongolia leads to the largest reduction of grassland, which is 65570,26379 and $25350 \mathrm{~km}^{2}$ respectively. There was $50834 \mathrm{~km}^{2}$ (in Xinjiang) and $76285 \mathrm{~km}^{2}$ (in Qinghai) grassland caused by the conversion to the bare land. The conversion of Ningxia grassland to cropland; and bare land led to a net loss of 5977 and $1570 \mathrm{~km}^{2}$ respectively, but at the same time, $5265 \mathrm{~km}^{2}$ of cropland was transferred to grassland. Meanwhile, the net reduction of grassland to forest and bare land in Shaanxi was 1016 and $648 \mathrm{~km}^{2}$.

From 2005 to 2015 , the grassland area in the study area decreased by $11,414 \mathrm{~km}^{2}$, equivalent to 
$0.46 \%$ of the grassland in 2005 . The decrease of grassland is mainly the mutual transfer of grassland and cropland, with a total reduction of $9,150 \mathrm{~km}^{2}$. The increase of grassland was mainly from cropland and bare land, resulting in $5845 \mathrm{~km}^{2}$. For pastoral areas, the decrease of grassland area concentrated in Xinjiang, Shaanxi and Ningxia, and the reduction rates were 17.37\%, 1.797\% and $1.92 \%$ respectively. The conversion of grassland to bare land in Xinjiang and Tibet was 153 $\mathrm{km}^{2}$ and $264 \mathrm{~km}^{2}$ respectively, while the net increase of 245 and $221 \mathrm{~km}^{2}$ in Gansu and Ningxia Hui Autonomous Region was from bare land. Since the conversion from grassland to cropland and bare land happened, more pastoral grassland has reduced, and it was $821 \mathrm{~km}^{2}$ in Inner Mongolia, $209 \mathrm{~km}^{2}$ in Ningxia, $115 \mathrm{~km}^{2}$ in Shaanxi Province, and $265 \mathrm{~km}^{2}$ to grassland at the same time.

\section{Changes in pattern of grassland landscapes}

The SHDI and SHEI in the whole study area increased slowly, whereas the landscape heterogeneity increased. Among the seven pastoral areas, the SHDI and SHEI in Xinjiang, Gansu, Shaanxi and Ningxia were decreased. However, the SHDI in Qinghai Province increased from 2005 to 2015, whereas the SHEI was relatively flat. This finding showed that the landscape pattern in Qinghai Province was complex, and the spatial distribution of land cover/land use types was uneven. The SHDI and SHEI in Tibet show an increasing trend from 1985 to 1995 but a decreasing trend from 1995 to 2015 . This result showed that the landscape pattern in Tibet was simple, and the space of each land cover type was evenly distributed.

In the study area, the number of patches was the smallest in 1985 and 1995, whereas the mean patch size value was the largest. The change indicated that the degree of fragmentation and spatial heterogeneity of grassland was low in 1995. The NP and MPS variations in different provinces were inconsistent. In 2015, the NP in Inner Mongolia and Gansu was the lowest, whereas the MPS was the highest, indicating that the pasture fragmentation and spatial heterogeneity of the two pastoral areas were the lowest in 1995. Inner Mongolia, Gansu, Qinghai and Ningxia reached the minimum NP and maximum MPS in 2015. However, Xinjiang had the smallest NP and highest MPS in 1985 and 1995, revealing that grass fragmentation and spatial heterogeneity were the lowest during these years. 
- whole study area

Ningxia Hui Autonomous Region

- Inner Mongolia Autonomous Region

Gansu Province

Qinghai Province

- Shaanxi Province

$\rightarrow$ Xinjiang Uygur Autonomous Region

Tibet
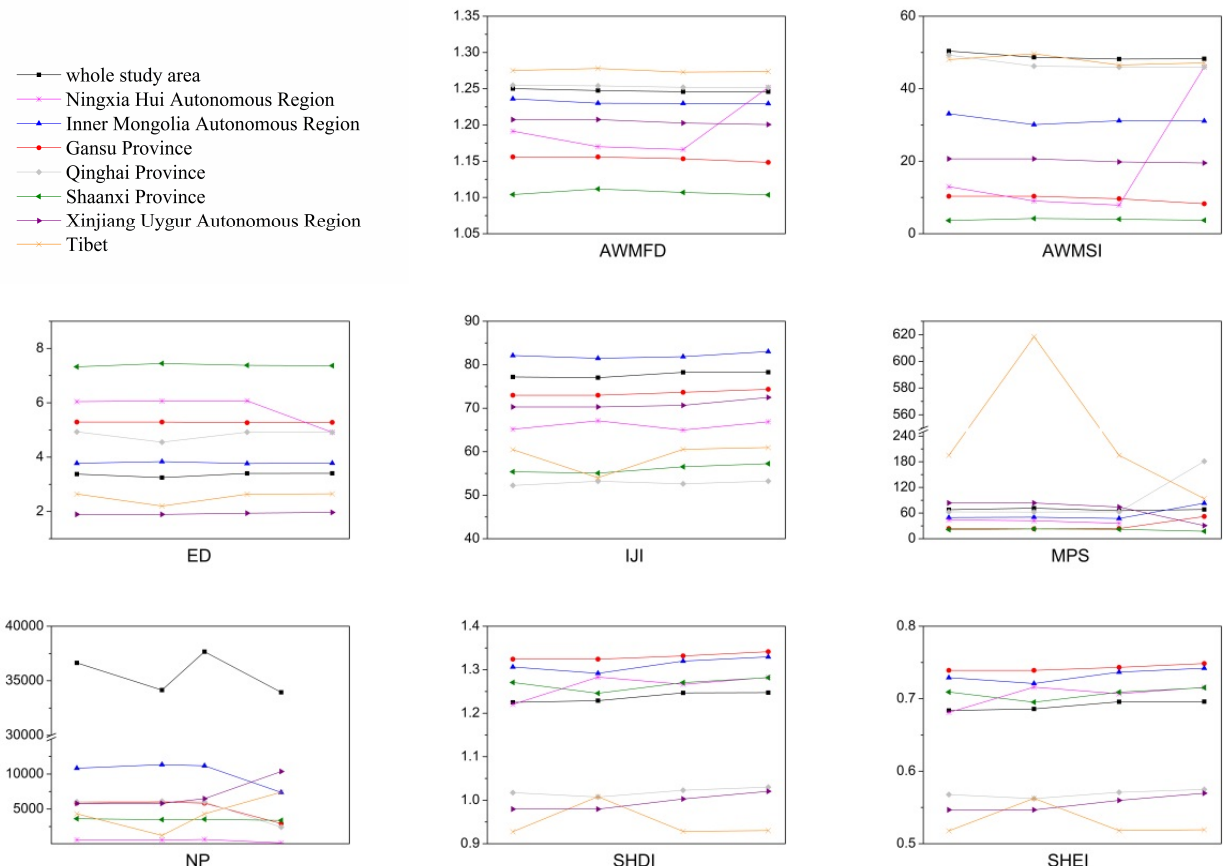

Fig. 6: Changes in landscape index for the whole study area and the 7 provinces during 1985-2015

Note: AWMFD::area weighted mean fractal dimension, AWMSI::area weighted mean shape index, ED::edge density, IJI: interspersion juxtaposition index, MPS: mean patch size, NP: number of patches, SHDI: Shannon's diversity index, SHEI: Shannon's evenness index

Except for Ningxia, no significant difference in the ED of grassland vegetation was found between 2005 and 2015, indicating no significant change in grass fragmentation and marginal effect. The AWMSI at the regional scale was high in 1985 and 1995, but low in 2005 and 2015. Hence, the grass patch shape in the whole area was simplified and regularized from 1995 to 2005 . The AWMSI in Qinghai, Inner Mongolia and Gansu showed basically the same rules of variation with the whole study area. However, the AWMSI increased sharply in Ningxia in 2005-2015, which indicates that the patch shape of grassland in the province was complicated, and the edge effect increased.

The AWMFD in the entire study area did not change in many years. The grassland landscape pattern was not affected by human activities. The trends of AWMFD in Inner Mongolia, Tibet, and Qinghai are similar to those in the entire study area. However, Tibet has the largest AWMFD, which indirectly reflects that the grassland landscape pattern in this province is less affected by human activities. This phenomenon is also caused by the unique geographical location of Tibet. The AWMFD in Gansu and Shaanxi was the highest in 1995 and 2005 but was low in 1985 and 2015 , indicating that the effect of human interference on grassland landscape pattern was less in 
1985-1995 but increased in 2005-2015 and 1995. In 2005, less interference was observed from humans. In Xinjiang, AWMFD remained unchanged from 1995 to 2005 but increased sharply from 2005 to 2015, indicating that grassland in Xinjiang was reduced by human interference. In addition, IJI increased throughout the study area and in the seven provinces and regions between 2005 and 2015. The connectivity and cohesion of grass patches decreased, but IJI declined significantly in Tibet during 1985-1995 and in Ningxia during 1995-2005. This finding shows that the patch connectivity and cohesion of grassland are greatly improved.

\section{Changes in NPP of grassland}

The spatial distribution of average grassland NPP shows evident heterogeneity. The areas with high NPP values are distributed in the northeastern Inner Mongolia, Xinjiang Tianshan, and the Al Taishan region southern Shaanxi, southern Gansu, the source of three rivers, Qilian Mountains, the southeast of Tibet, northwest of Tibet, and the southern of Xinjiang the grassland NPP values are the lowest. The average NPP of grassland in the entire study area increased by $25.99 \%$, $14.35 \%$, and $41.46 \%$ from 1985 to 1995,2005 to 2015 , and 1985 to 2015 , respectively. The average NPP in 1995-2005 was reduced by $2.98 \mathrm{gC} / \mathrm{m}^{2}$, which is equivalent to $1.81 \%$ of the average NPP in 1995. The changes in various provinces are as follows. The average NPP of grassland in Xinjiang slightly changed from 1995 to 2005 and then increased by 32.03 and 9.24 $\mathrm{gC} / \mathrm{m}^{2}$ in 1985-1995 and 2005-2015, respectively. The average NPP in Tibet was obtained in 1995-2005. The value was reduced by $34.89 \mathrm{gC} / \mathrm{m}^{2}$ but increased by 30.80 and $35.96 \mathrm{gC} / \mathrm{m}^{2}$ in 1985-1995 and 2005-2015, respectively. The average NPP change of grassland in Qinghai province increased by 15.44 and $18.24 \mathrm{gC} / \mathrm{m}^{2}$ frame 1985 to 1995 and 1995 to 2005 . The increase from 2005 to 2015 was $26.50 \mathrm{gC} / \mathrm{m}^{2}$. The average NPP in Inner Mongolia grassland decreased by $34.89 \mathrm{gC} / \mathrm{m}^{2}$ from 1995 to 2005 , which is equivalent to the value in 1995 that is $17.51 \%$ of grassland NPP. The grassland NPP in Gansu Province changed slightly from 1985 to 2005 but increased by $57.63 \mathrm{gC} / \mathrm{m}^{2}$ from 2000 to 2010 . Shaanxi Province showed an increasing trend of NPP from 1985 to 2015 with a total increase in 30 years. At $133.95 \mathrm{gC} / \mathrm{m}^{2}$, NPP in grassland decreased from 1995 to 2005 , with a decrease of $-24.72 \mathrm{gC} / \mathrm{m}^{2}$, and an increase of $45.43 \mathrm{gC} / \mathrm{m} 2$ from 2005 to 2015 , which was equivalent to $38.24 \%$ of NPP in 2005 . 


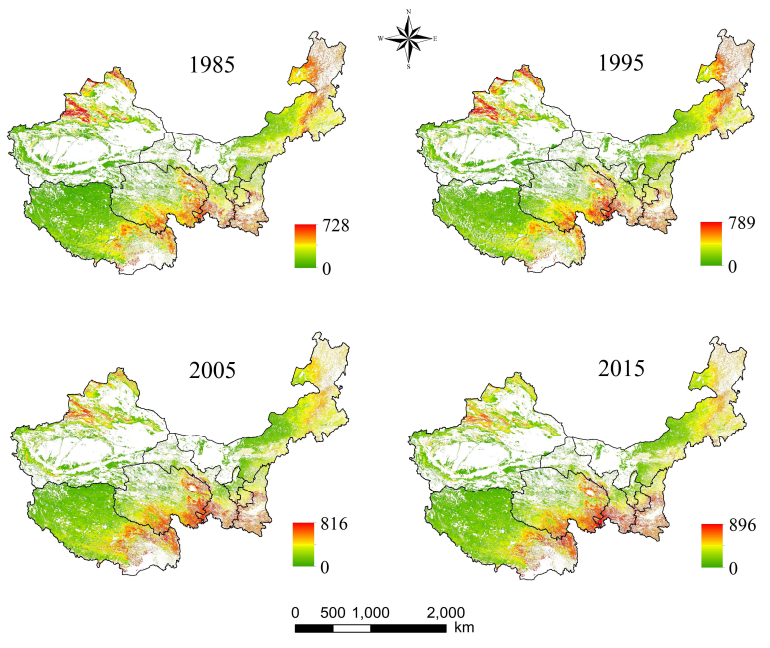

Fig 7: The spatial distribution of grassland mean NPP during 1985-2015

Table 1: The grassland annual mean NPP changes during 1985-2015/(g C/m²

\begin{tabular}{|c|c|c|c|c|c|c|c|c|}
\hline Sections & study area & Tibet & Innner & Xinjiang & Qinghai & Gansu & Shanxi & Ningxia \\
\hline \multicolumn{9}{|c|}{ Mongolia } \\
\hline 1985 & 130.45 & 90.34 & 168.46 & 105.26 & 178.12 & 159.85 & 234.38 & 124.41 \\
\hline 1995 & 164.35 & 119.56 & 199.26 & 137.29 & 193.56 & 217.71 & 281.00 & 143.53 \\
\hline 2005 & 161.37 & 135.63 & 164.37 & 127.49 & 211.80 & 218.59 & 292.44 & 118.81 \\
\hline 2015 & 184.53 & 145.89 & 200.32 & 136.73 & 238.30 & 276.22 & 368.33 & 164.24 \\
\hline \multicolumn{9}{|c|}{ Percentage change $(\%)$} \\
\hline $1985-1995$ & 25.99 & 32.34 & 18.28 & 30.43 & 8.67 & 36.19 & 19.89 & 15.37 \\
\hline 1995-2005 & -1.81 & 13.44 & -17.51 & -7.14 & 9.42 & 0.40 & 4.07 & -17.22 \\
\hline $2005-2015$ & 14.35 & 7.57 & 21.88 & 7.25 & 12.51 & 26.36 & 25.95 & 38.24 \\
\hline $1985-2015$ & 41.46 & 61.49 & 18.91 & 29.90 & 33.79 & 72.80 & 57.15 & 32.01 \\
\hline
\end{tabular}

Table 2: The grassland total NPP variations during 1985-2015/(Tg C)

\begin{tabular}{ccccccccc}
\hline Sections & study area & Tibet & Innner & Xinjiang & Qinghai & Gansu & Shanxi & Ningxia \\
& \multicolumn{7}{c}{ Mongolia } \\
\hline 1985 & 322.34 & 75.77 & 90.10 & 50.65 & 24.65 & 60.19 & 17.77 & 3.21 \\
1995 & 398.95 & 90.64 & 113.34 & 66.06 & 73.34 & 30.01 & 22.05 & 3.47 \\
2005 & 395.08 & 113.65 & 86.16 & 60.02 & 79.63 & 30.31 & 22.50 & 2.84
\end{tabular}




\begin{tabular}{ccccccccc}
2015 & 452.16 & 122.40 & 105.20 & 64.36 & 89.56 & 38.36 & 28.34 & 3.95 \\
\multicolumn{2}{l}{ Percentage change (\%) } & & & & & & & \\
$1985-1995$ & 23.77 & 19.63 & 25.80 & 30.44 & 197.54 & -50.15 & 24.09 & 23.77 \\
$1995-2005$ & -0.97 & 25.40 & -23.98 & -9.14 & 8.57 & 1.00 & 2.04 & -0.97 \\
$2005-2015$ & 14.45 & 7.69 & 22.10 & 7.22 & 12.48 & 26.59 & 25.95 & 14.45 \\
$1985-2015$ & 40.28 & 61.55 & 16.76 & 27.07 & 263.34 & -36.26 & 59.48 & 40.28 \\
\hline
\end{tabular}

The total NPP in grassland in the study area was the highest in 2015, which was $452.16 \mathrm{Tg}$ C. This value was $40.28 \%, 13.24 \%$, and $14.45 \%$ higher than that in 1985 , 1995, and 2005 , respectively. The changes in different provinces and regions are quite different. The total grassland NPP in Xinjiang increased by $30.44 \%$ from 1985 to 1995 but decreased by $9.14 \%$ in 2005 . The total grassland NPP in Tibet showed an increasing trend at each stage from 1985 to 2015 . When the average NPP value increased by $61.49 \%$ in 2015 , the total NPP value increased by $61.55 \%$, though the grassland area in Tibet decreased by $0.17 \%$ in $1985-2015$. The total NPP in grassland in Qinghai Province has increased from 1985 to 2015, especially in 1985-1995 with an increase of 197.54\%. When the average NPP of grassland increased from 2005 to 2015, the total NPP also increased. The total amount of NPP in Inner Mongolia in 2005 was $-23.98 \%$ lower than that in 1995 because the grassland area and average NPP were reduced by $-8.05 \%$ and $17.51 \%$ respectively, whereas the total amount of NPP increased by $22.10 \%$ from 2005 to 2015 . The total amount of grassland NPP in Gansu Province decreased by -50.15\% between 1985 and 1995 but increased by $26.59 \%$ between 2005 and 2015 . The change rule of total NPP in Shaanxi grassland is consistent with the change in average NPP. The value showed an increasing trend from 1985-2015 with a total increase of $10.57 \mathrm{Tg}$ C. The total NPP in Ningxia grassland was the highest in 2015 with an increase of $38.73 \%$ compared with that in 2005 .

\section{Conclusion}

The conclusion shows (1) The sizes of the grassland study area in 1985, 1995, 2005, and 2015 were $248.34,243.93,245.80$, and 244.66 million $\mathrm{km}^{2}$, respectively. From 1985 to 2015, the grassland was reduced by $36,800 \mathrm{~km}^{2}$.(2) The heterogeneity of the landscape pattern increased during 1985-2015. The degrees of fragmentation and spatial heterogeneity of grassland were both 
low in 1985 and 1995. The shape of grass patches was simplistic and regular in 2005-2015. (3) The average NPP of grassland has significant regional differences in spatial distribution. The total size of grassland NPP in the study area was the lowest in 2005 but reached the greatest in 2015 .

\section{Discussion}

\section{Influence of climate change on landscape pattern and grassland productivity}

Climate change is the main factor for the inter-annual change of terrestrial vegetation activity (Keeling et al 1996; Weltzin et al 2003).,it mainly affects the growth of grassland vegetation by the changes in temperature and precipitation. The increasing precipitation in arid regions is conducive to the growth of forage grass (Yang et al 2008). By contrast, the increase in temperature also increases vegetation and soil evapotranspiration but reduces available soil moisture. This phenomenon makes the environment arid and not conducive to forage growth (Shen et al 2012). In the context of global climate change, China's climate has also undergone corresponding changes. To analyze the climate change patterns in the study area, this paper collected temperature and precipitation data from 1961 to 2010. The trend of changes and the regularity of anomalies were also evaluated.

The annual temperature in the study area has gradually increased from 1961 to 2010, with an increase rate of $0.39^{\circ} \mathrm{C} / 10$ year, which is higher than the rate of annual temperature increment of $0.17^{\circ} \mathrm{C} / 10$ year from 1951 to 2000 in China. The inter-annual rate in annual precipitation is 5.2 $\mathrm{mm} / 10$ year,. The annual fluctuation of precipitation is relatively large, especially in 1998 , due to the increment in flood water (Zhu, W. Q 2005b). The precipitation is abnormally high and was affected by strong El Niño in 1982. With the drought in north and south of China, the precipitation is lower than the annual average. Some studies reported that China's precipitation did not change significantly during 1951 to 2000 . However, the precipitation in different regions was different (Shi et al 2007). The regions where precipitation increased significantly were located in northern China, the northwestern arid regions, and the Tibetan Plateau. A previous report is basically consistent with the conclusions in the current paper that the temperature in the study area has continued to increase during the past 50 years, and the precipitation has not changed significantly. However, since 1980s, the climate in the arid northwestern China has transformed from warm to 
warm and humid. Significant differences, such as the trend of warming and drying in Inner Mongolia from 1951 to 2010, are observed in the precipitation changes in different regions (Liu \& Wang 2012; Lu et al 2009).

During 1981-2010, precipitation increased, and in 20 years, the 20-year precipitation anomaly was positive. The precipitation increased from $318 \mathrm{~mm}$ in 1980s to $324 \mathrm{~mm}$ in 2000-2010, an increase of $2 \%$. However, the temperature continued to increase from $5.5^{\circ} \mathrm{C}$ in $1980 \mathrm{~s}$ to $6.75{ }^{\circ} \mathrm{C}$ in $2000-2010$, an increase of $1.25^{\circ} \mathrm{C}$. Some studies have suggested that with a temperature increase of $1{ }^{\circ} \mathrm{C}$, the annual potential evapotranspiration (PET) increases by $5.25 \%+1.55 \%$ (Le 1996). Therefore, the increase in precipitation is not sufficient to offset the increase in temperature, resulting in increased drought, vegetation, and evapotranspiration. The reduction on soil moisture and such climatic conditions are the basis for desertification. Coupled with the interference of human activities, such as overgrazing and indiscriminate digging, these phenomena lead to grassland desertification and ultimately to the original vulnerability of grassland to desert transformation. During 1985-1995 and 2005-2015, large areas of grassland were migrated to the desert. A small portion of deserts shifted to grassland during 1995-2005. This migration was mainly due to the $10.75 \%$ increase in grassland area in Tibet during the period and was the reason for the increase in grassland area in the district (Akiyama \& Kawamura 2007; Teague \& Dowhower 2003; Zha 2004). Although human activities have always been considered as the dominant driving factor in grassland degradation, climate aridity accelerates the development of grassland degradation to a certain extent, especially in the arid-semi-arid regions of northwestern China. The continuous increase in temperature from 1961 to 2010 promotes the conversion of grassland to desert at some extent (Han et al 2008). In addition, studies in the Hun shandake Sandy Land have also confirmed that climate change plays an important role in desertification (Yang 2010). 

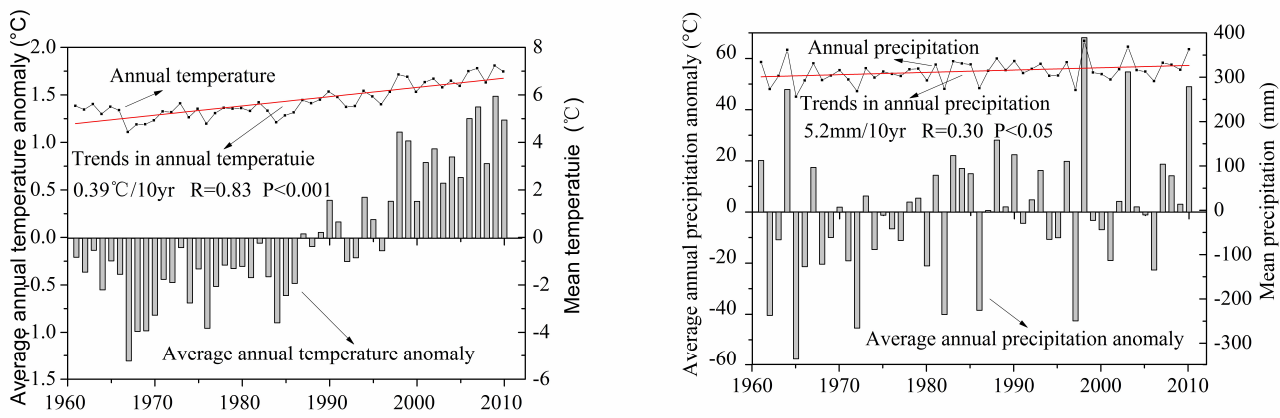

Fig 8: The inter-annual changes of the mean temperature, precipitation and anomaly during 1961-2010

\section{Effects of human factors on grassland coverage area and productivity}

\section{Effect of overgrazing}

Overloaded grazing is the main driving force for grassland degradation in China and is particularly prominent in grassland degradation in northern China (Akiyama \& Kawamura 2007). The degradation of grassland in China began in the 1960s. Since then, the degraded area of grassland in China has increased at a rate of $15 \% / 10$ year (Wang et al 2005). In the past 10 years, the degradation rate of grassland in China has increased from $55 \%$ to $90 \%$ (Du, Q. L 2006). The rapid increase in population and economic development has led to a sharp increase in the demand for animal husbandry products and eventually to a rapid increase in the number of grazing animals. The number of grazing animals in China increased from 11.9 million in 1950s to 61.3 million in 2001 based on the statistics found in China. The total number of livestock showed a rapid increase from 1978 to 2011 (Fig 10.), though the number of livestock has decreased since 2003. Overgrazing occurs on a large area of grassland, and the grassland can no longer recuperated under the constant stamping and feeding disturbances . In some arid areas, grassland overloading rate has reached $50 \%-120 \%$ or even $300 \%$. As shown in Figure 9., overloaded grazing occurred in all six provinces in Northwest China, except for Shaanxi Province. The number of livestock in Xilin Gol League in Inner Mongolia increased from 2 million in 1977 to 18 million in 2000, causing about one-third of grassland degradation. As of 1995, China's degraded grassland area accounted for 50.2\% (Lv, Z. J et al 2005) of China's available grassland area. As of 1999, 32\% of grassland in Inner Mongolia was overloaded with grazing, whereas $60 \%$ had varying degrees of 
degradation (Du, Q. L 2006).

Under continuous overgrazing, animal feeding and stamping will reduce grassland vegetation, coverage, and productivity. At the same time, animal stamping will change the soil structure, increase soil hardness, reduce the effective soil moisture, and expose patches on the surface. This phenomenon provides conditions for wind erosion desertification (Zhu, Z. D 1997). The results indicate that, except for the increase in grassland area between 1995 and 2005, the grassland area showed a decreasing trend that is mainly due to the shift of grassland to desert and farmland. Approximately 468,800 km2 of grassland was converted to other lands during 1985-2015. For the utilization types, $46.05 \%$ were converted to desert, and $23.42 \%$ were converted to farmland, which ultimately led to a net decrease of $1.48 \%$ in grassland area.

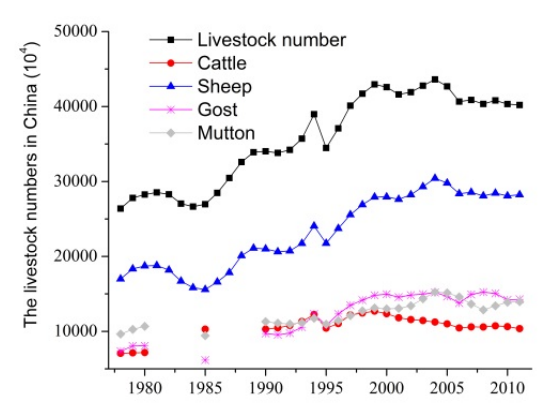

1 2

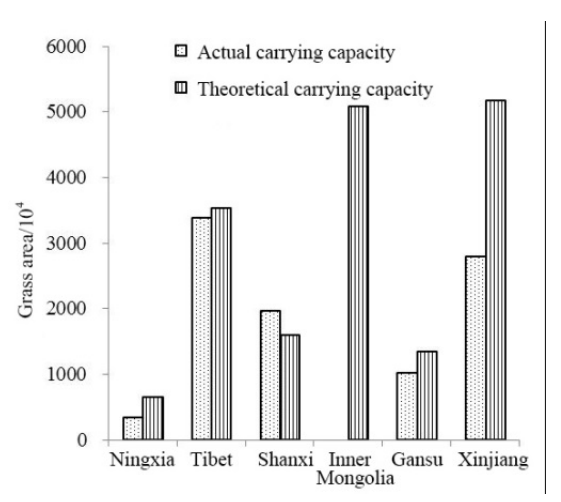

Fig 10: The grassland overgrazing situation in $4 \quad$ main animal husbandry provinces

\section{Influence of grassland reclamation}

Rapid population growth has rapidly increased food demand, and grassland has been reclaimed as farmland on a large scale (Jiang \& Wu 2006). Under the guidance of the "grain as the key" policy, a large area of grassland has rapidly undergone sandy desertification. From 1949 to 1999, 193,000 $\mathrm{km}^{2}$ of grassland was reclaimed as farmland, and $18.2 \%$ of China's increased farmland area originated from grassland reclamation. Between 1958 and 1976, 20,000 km2 of grassland was reclaimed into farmland in Inner Mongolia (Chuluun \& Ojima 2002). This shift took place mainly in the agro-pastoral ecotone. During urbanization, grasslands around the city were reclaimed to meet the food demand. This study finds that from 1985 to $2015,109,800 \mathrm{~km} 2$ of grassland was 
reclaimed as farmland, whereas $85,700 \mathrm{~km}^{2}$ of farmland was converted into grassland. This mutual conversion between farmland and grassland did not significantly reduce the total grass area. However, the overall quality of the grassland was reduced during conversion. Considering that most of the grasslands that were reclaimed as farmland belong to high-quality pasture grasslands, the grasslands transformed from farmland are mostly abandoned lands or land with low productivity (Qi et al 2012). This kind of grassland reclamation often ends in failure, especially in the dry grassland area. Approximately $30 \%-80 \%$ of the reclamation farmland gradually degenerates and is finally abandoned. After the grassland has been reclaimed, especially in a continuous arid environment, it will be degraded into desertified land with lost productivity and destroyed land resources after 30 years. Xinjiang had a net reduction of 97,428 km2 in grassland from 1985 to 2015 , which was equivalent to $20.20 \%$ in 1985 . This phenomenon was mainly due to the continuous increase in temperature and glacial meltwater, which led to a drastic increase in grassland land reclamation and a large area of grassland degradation to desertification. The joint action of the people led to the reduction of grassland area.

The direct consequence of grassland degradation is the decline in grassland productivity. According to statistics, the current grass yield per unit area decreased by $30 \%$ to $50 \%$ compared with that in 1960s. Inner Mongolia grassland surveys showed that the above-ground NPP in Inner Mongolia grassland decreased by 53\% (Qi et al 2012) from 1961 to 2010. This decrease is mainly due to overgrazing and climate change. The changes in temperature and precipitation over the past 30 years are shown in Figure 6.10. The trend of aridity development in central and eastern Inner Mongolia and Shaanxi Province is clear. Therefore, the combination of overloaded grazing and climate drought reduced NPP in Inner Mongolia and Shaanxi Province during 1995-2005. The average NPP of grassland in the year was significantly low with a decrease of $20.04 \%$ and $2.03 \%$. However, for the entire study area, the grassland NPP showed an increasing trend due to the significant increase in NPP in the grasslands of Xinjiang, Tibet, Qinghai, Gansu, and Ningxia. This increase may be due to increased precipitation in most parts of Xinjiang. In particular, the precipitation in Tianshan, Altai Mountains, southern Xinjiang oasis, southwestern Tibet, most parts of Qinghai, and northwestern Gansu generally increased. This phenomenon promoted the growth of pasture, improved grassland quality, and consequently increased NPP. 


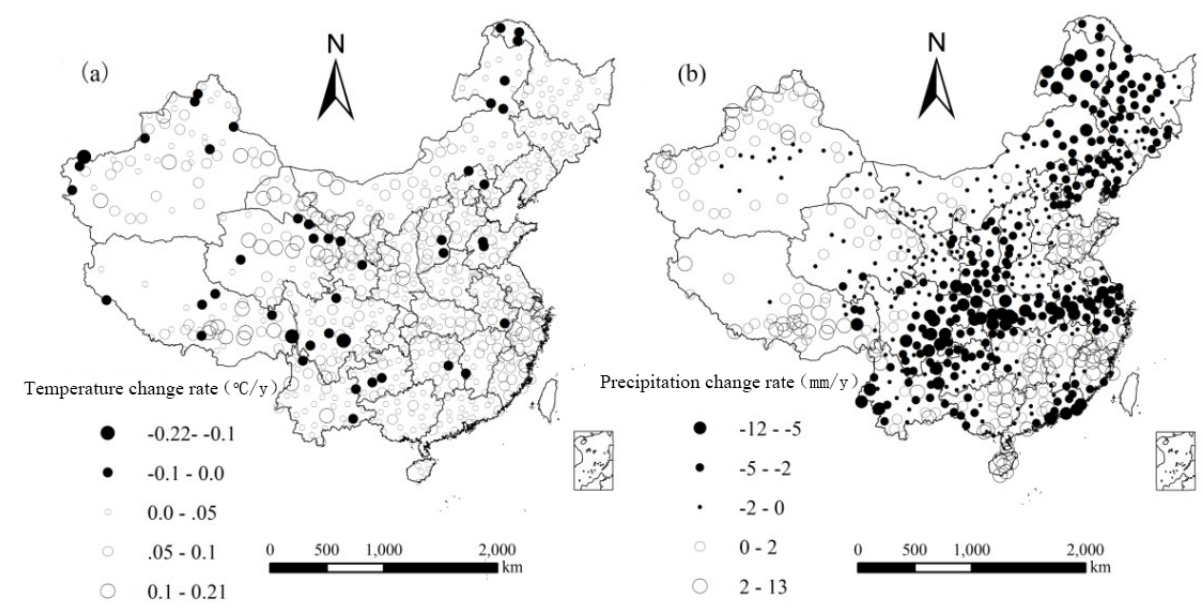

Fig 11: The inter-annual changing trend of temperature and precipitation in China during

1982-2010

\section{Effects of ecological restoration measures on grassland productivity}

The Chinese government's protection of grassland ecosystems began with the enactment of the Grassland Law in 1985. Later, the government established a series of laws and regulations concerning the protection of grassland resources and desertification. However, the deterioration of grassland in the north and the frequent occurrence of dust storms have recently pushed the Chinese government to put importance to the protection of grassland ecosystems and the restoration of degraded ecosystems(Zhang et al 2012). Since 1999, the Chinese government has successively issued the project of returning farmland to forests and returning grazing land to grassland. The implementation of ecological restoration projects has played a positive role in the restoration of degraded grassland and the protection of grassland resources (Liu et al 2008; Tong et al 2004).

The project of returning farmland to forests and grass that began in 1999 was piloted in Gansu, Shaanxi, and Sichuan. By 2002, the project was expanded to 25 provinces and autonomous regions. This project mainly included the following restoration measures: conversion of degraded sloping farmlands into forests or grasslands, and closure of mountains and forests, and planting of artificial grass. This study found that the mutual transformation between farmland and grassland from 1985 to 2015 was conducive to an increase in the area of grassland, resulting in a net 
increase of $87,600 \mathrm{~km} 2$ of grassland. The newly added grassland is distributed around the original grassland, which is beneficial to the improvement of the structure and function of the ecosystem. This procedure is also conducive to the conservation of biodiversity and the improvement of the stability of the ecosystem. Therefore, the conversion of farmland to grassland or forest is beneficial to ecosystem restoration.

The project of returning farmland to forests and grasslands may positively affect the reversal of desert to grassland in the study area from 2000 to 2010. As shown in Figure 6.11.a, the data show that the artificial grass planting in the study area increased rapidly from 2001 to 2003, reaching 1.72 million hectares in 2003 and accounting for $80 \%$ of the total area of artificial grass planted in China. Aircraft sowing and grass seed also showed improvement The large increase in acreage and the combined effect of the three measures have increased the annual fluctuations in the area of newly added grass (Figure 6.11.b), reaching a maximum of 4.81 million hectares in 2006 and accounting for $60 \%$ of the national total; The former and newly added grass areas accounted for the largest proportion (50\% and 58\%) in the study area and dictated the trend of the two indicators. The artificial planting of grass and aircraft sowing will gradually expand the grassland area into the desert to achieve the purpose of "people entering the sand and receding." On the one hand, improved planting of grass species will make planting pasture suitable for the arid ecological environment. On the other hand, the excellent pasture can improve the pasture production. With the increase in grassland coverage, scattered grassland grows in patches, the degree of fragmentation decreases and the dominance increases. Ultimately, the stability of grassland ecosystems increases, and productivity increases.

To further promote the restoration of degraded grassland and the protection of grassland resources and improve the frequency of dust storms, the Chinese government began implementing the project of returning grazing to grassland in 2003. The grazing pressure was attenuated through measures, such as grazing bans, grazing and rotational grazing, and degrading. The grass is then restored. From 2001 to 2010, the grazing prohibition area increased yearly in all provinces and regions in the northwestern province. In 2010, the grazing prohibition area in the seven provinces and regions accounted for $78 \%$ of the country's area. The prohibition of grazing area in Inner Mongolia accounted for $38 \%$ of the grazing prohibited area in the country. A relatively high ban 
was placed on grazing in Shaanxi and Gansu Province $(12.5 \%, 10 \%)$. The area of fenced enclosures has increased significantly (Figure 6.11.d). The area enclosed by fences in the seven provinces and autonomous regions accounts for $85 \%$ of the total fenced area, and the fenced area in Inner Mongolia accounts for $40 \%$ of the country's total.

Grazing and fencing greatly reduce the pressure on grassland grazing. Without external interference, the biodiversity, stability and productivity of grassland ecosystems can be recovered quickly (Bai et al 2004), and long-term enclosed fences with large areas will increase the coverage of grassland. For a piece of degraded desert grassland in Alxa, the vegetation coverage has increased by $50 \%$, and biomass has increased by 56\% (Pei et al 2008) after 6 years of prohibiting grazing. The number of years of closure increased, and grassland biomass and soil carbon density continued to increase (Jia, H. T et al 2009; Huo, W. L et al 2004). After the implementation of ecological restoration measures in Maqu County, Gansu Province, the grassland was significantly improved (Wang, J et al 2009).

This study also found that the project of returning farmland to forests and grassland has the highest intensity in Inner Mongolia with evident ecological effects. This finding can be verified from the above-mentioned changes in artificial grass, fence enclosure and grazing prohibition areas, and grassland landscape index. From 1995 to 2005, SHDI and SHEI decreased, whereas ED, IJI, and AWMSI decreased. The change of landscape index showed that the dominance of Inner Mongolia grassland increased, the degree of fragmentation decreased, the cohesion of spatial distribution increased, and the shape of plaque became regular. The reason was as follows: the arid climate in 1995-2010 and the opening and overgrazing of grassland were still serious (Wang et al 2004). After the implementation of the national ecological restoration measures, some desertification areas, such as Horqin Sandy Land and Mao Usu Sandy Land, have undergone a significant reversal of desertification. However, overall desertification is continuously intensifying. From 1986 to 2000, human activities played a decisive role in the development and reversal of desertification in Yulin, Shaanxi. In Xinjiang, Tibet and Qinghai, the relative proportion of grazing bans and fenced areas is relatively low (Sun et al 2012). Therefore, the intensity of returning livestock to grassland, not just typical and severely degraded areas, must be increased. 

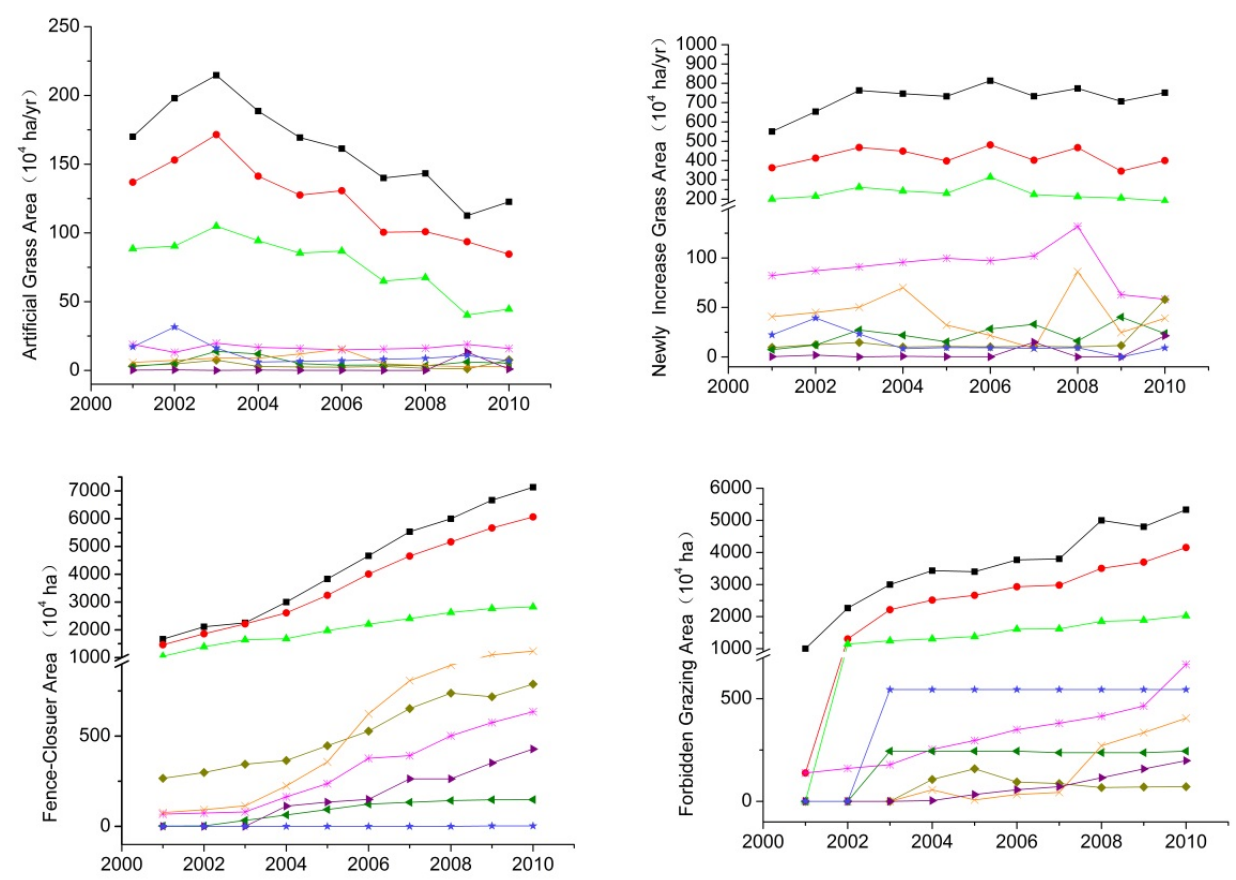

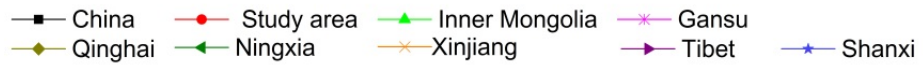

Fig 12: The artificial grass area in China (a), the newly increase grass areas each year (b), the fence-closure area(c), and forbidden grazing area (d) during 2001-2010

\section{References:}

Akiyama T, Kawamura K: Grassland degradation in China: Methods of monitoring, management and restoration. Grassland Science 53:1-17, 2007.

Al JE, Paasche: IPCC. Climate Change 2007: The Physical Science Basis. Contribution of Working Group I to the Fourth Assessment Report of the Intergovernmental Panel on Climate Change. Cambridge University Press: Cambridge, UK, 2007.

Bai Y, Han X, Wu J, et al.: Ecosystem stability and compensatory effects in the Inner Mongolia grassland. Nature 431:181-184, 2004.

Cao S: Impact of China's Large-Scale Ecological Restoration Program on the Environment and Society in Arid and Semiarid Areas of China: Achievements, Problems, Synthesis, and Applications.

Critical Reviews in Environmental Science \& Technology 41:317-335, 2011.

Chuluun T, Ojima D: Land use change and carbon cycle in arid and semi-arid lands of East and Central Asia. Science in China Ser C 45:48-54, 2002.

Conant RT, Paustian K, Elliott ET: GRASSLAND MANAGEMENT AND CONVERSION INTO

GRASSLAND: EFFECTS ON SOIL CARBON, in Ecological Applications,2001, 2001, pp. 
$343-355$.

Han JG, Zhang YJ, Wang CJ, et al.: Rangeland degradation and restoration management in China. Rangeland Journal 30:233-239, 2008.

Jiang G, Wu J: Restoration and Management of the Inner Mongolia Grassland Require a Sustainable Strategy. Ambio 35:269, 2006.

Kang L, Han X, Zhang Z, et al.: Grassland ecosystems in China: review of current knowledge and research advancement. Philos Trans R Soc Lond B Biol Sci 362:997-1008, 2007.

Keeling CD, Chin JFS, Whorf TP: Increased activity of northern vegetation inferred from atmospheric $\mathrm{CO}_{2}$ measurements. Nature 382:146-149, 1996.

Le HH: Climate change, drought and desertification. Ipcc Working Group II Adaptation \& Mitigation Subgr 3:133-185, 1996.

Liu J, Li S, Ouyang Z, et al.: Ecological and socioeconomic effects of China's policies for ecosystem services. Proc Natl Acad Sci U S A 105:9477-9482, 2008.

Liu S, Wang T: Climate change and local adaptation strategies in the middle Inner Mongolia, northern China. Environmental Earth Sciences 66:1449-1458, 2012.

Lu N, Wilske B, Ni J, et al.: Climate change in Inner Mongolia from 1955 to 2005-trends at regional, biome and local scales. Environmental Research Letters 4:45006, 2009.

Nan Z: The grassland farming system and sustainable agricultural development in China. Grassland Science 51:15-19, 2005.

Ni J: Carbon storage in grasslands of China. Journal of Arid Environments 50:205-218, 2002.

Pei S, Fu H, Wan C: Changes in soil properties and vegetation following exclosure and grazing in degraded Alxa desert steppe of Inner Mongolia, China. Agriculture Ecosystems \& Environment $124: 33-39,2008$.

Qi J, Chen J, Wan S, et al.: Understanding the coupled natural and human systems in Dryland East Asia. Environmental Research Letters 7:15202-15207, 2012.

Ren JZ, Hu ZZ, Zhao J, et al.: A grassland classification system and its application in China. Rangeland Journal 30:199-209, 2008.

Scurlock JMO, Hall DO: The global carbon sink: a grassland perspective. Global Change Biology $4: 229-233,2010$ 
Shen W, Li H, Sun M, et al.: Dynamics of aeolian sandy land in the Yarlung Zangbo River basin of Tibet, China from 1975 to 2008. Global \& Planetary Change s 86-87:37-44, 2012.

Shi Y, Shen Y, Kang E, et al.: Recent and Future Climate Change in Northwest China. Climatic Change 80:379-393, 2007.

Sun JG, Wang T, Yan CZ: The Relative Roles of Climate Change and Human Activities in Desertification Process:A case study in Yulin,Shaanxi Province,China. Journal of Desert Research 74:498-507, 2012.

Teague WR, Dowhower SL: Patch dynamics under rotational and continuous grazing management in large, heterogeneous paddocks. Journal of Arid Environments 53:211-229, 2003.

Tong C, Wu J, Yong S, et al.: A landscape-scale assessment of steppe degradation in the Xilin River Basin, Inner Mongolia, China. Journal of Arid Environments 59:133-149, 2004.

Wang T, Zhu ZD, Zhao HL: Study on Sandy Desertification in China 4. Strategy and Approach for Combating Sandy Desertification. Journal of Desert Research 24:115-123, 2004.

Wang X, Han J, Dong Y: Recent Grassland Policies in China An Overview. Outlook on Agriculture $34: 105-110,2005$.

Wang X, Zheng D, Shen Y: Land use change and its driving forces on the Tibetan Plateau during 1990-2000. Catena 72:56-66, 2008.

Weltzin JF, Loik ME, Schwinning S, et al.: Assessing the Response of Terrestrial Ecosystems to Potential Changes in Precipitation. Bioscience 53:941-952, 2003.

Yang X: Climate Change and Desertification with Special Reference to the Cases in China, 2010.

Yang Y, Fang J, Ma W, et al.: Relationship between variability in aboveground net primary production and precipitation in global grasslands. Geophysical Research Letters 35:46-63, 2008.

Yu DY, Shi PJ, Han GY, et al.: Forest ecosystem restoration due to a national conservation plan in China. Ecological Engineering 37:1387-1397, 2011.

Zha Y: Assessment of grassland degradation near Lake Qinghai, West China, using Landsat TM and reflectance spectra data. International Journal of Remote Sensing 25:4177-4189, 2004.

Zhai P, Zhang X, Wan H, et al.: Trends in Total Precipitation and Frequency of Daily Precipitation Extremes over China. Journal of Climate 18:1096-1108, 2005.

Zhang G, Dong J, Xiao X, et al.: Effectiveness of ecological restoration projects in Horqin Sandy Land, 
China based on SPOT-VGT NDVI data. Ecological Engineering 38:20-29, 2012.

Zhou G, Wang Y, Wang S: Responses of grassland ecosystems to precipitation and land use along the Northeast China Transect. Journal of Vegetation Science 13:361-368, 2010.

Han, Y. W., Han, J. G., Zhang, Y. W. (2004). Soil and water conservation function of grassland vegetation in ecotone between agriculture and animal husbandry[J]. Journal of Soil and Water Conservation | J Soil Water Conserv18(4). 24-28. [In Chinese with English abstract]

Jia, H. R., Jiang, P. A., Zhao, C. W., Hu, Y. K., and Li, X. (2009) Effects of enclosure years on carbon distribution in grassland ecosystem [J]. Agricultural research in Arid Areas 27, 33-36. [In Chinese with English abstract]

Liu, J. Y., Liu, M. L., Zhuang, D. F., Zhang, Z. X. and Deng, X. Z.(2003) Study on spatial pattern of land-use change in China during 1995-2000[J]. Science in China Ser D, 46, 373-384. [In Chinese with English abstract]

Lv, Z. J., Lu, X. S., and Xin, X. P. (2005) The present situation and trend of grassland desertification in northern China[J]. Acta Agrectir Sinica | Acta Agrect Sin. 13, 24-27. [In Chinese with English abstract]

Ye, S. L., Wan, J. Y. and Guo, Q. H. (2001) Estimating Net Primary Productivity of Vegetation in China Using CASA Model[J]. Chinese Journal of Plant Ecology, 25, 603-608. [In Chinese with English abstract]

Ran, W, Qi S. F., Zhou, Z. G., Zhang, B.L. and Fu, H. (2004) Effects of Grazing and Enclosure on Soil Organic Carbon and Vegetation Characteristics in Grassland of Alashan Desert[J]. Journal of Gansu Forestry Science and Technology, 29, 4-6. [In Chinese with English abstract]

Wang, J., Guo, N., Cai, D. F., and Deng, Z. Y. (2009) Effect evaluation of grassland retreating grassland and grassland in Maqu County [J]. Acta Ecologica Sinica.29, 1276-1284. [In Chinese with English abstract]

Yang, Y. J., Jing, G. C.(2003) On grassland vegetation and land desertification[J]. Technology of Soil and Water Conservation, 44-45. [In Chinese with English abstract]

The ministry of agriculture of the People's Republic of China.(1996). Grassland resources in China.: Science and technology of China press.

Zhong, H. P., Fan, J.W., Yu, G. R., Han, B., Hu, Z. M., Yue, Y. Z., and Liang, Y. (2005) Research 
Progress of Carbon Cycle in Grassland Ecosystem. Acta Agrestia Sinica13, 67-73. [In Chinese with English abstract]

Zhou, D. W.. Jiang, S. C. and Wang. P,(2004) Problems and Countermeasures of Grassland Ecosystem Management in Northern China. Chinese Journal of Grassland26, 57-64. [In Chinese with English abstract]

Zhu, W. Q., Pan, (2005).. Remote Sensing Estimation of Net Primary Productivity of Terrestrial Ecosystem and Its Relationship with Climate Change in China. Beijing Normal University. [In Chinese with English abstract]

Zhu, W. Q., Pan, Y. Z., Long, Z. H., Chen, Y. H., Li, J., and Hu, H. B. (2005). Estimating net primary productivity of terrestrial vegetation based on GIS and RS: a case study in Inner Mongolia, China. Journal of Remote Sensing 9, 300-306. [In Chinese with English abstract]

Zhu, Z. D. (1997). Global change and desertification. Geoscience Frontiers. 213-219. [In Chinese with English abstract] 